\title{
Overexpression of vasopressin in the rat transgenic for the metallothionein-vasopressin fusion gene
}

\author{
H Nagasaki, H Yokoi, H Arima, M Hirabayashi ${ }^{1}$, S Ishizaki, \\ K Tachikawa, T Murase, Y Miura and Y Oiso \\ First Department of Internal Medicine, Nagoya University School of Medicine, 65 Tsurumai-cho, Showa-ku, Nagoya 466-8550, Japan \\ ${ }^{1}$ YS New Technology Institute Inc., 519 Shimoishibashi, Ishibashi-machi, Shimotsuga-gun, Tochigi 329-0512, Japan \\ (Requests for offprints should be addressed to H Nagasaki; Email: nagasaki@med.nagoya-u.ac.jp)
}

\begin{abstract}
Arginine vasopressin (AVP) is a major antidiuretic hormone, the overproduction of which causes diluting hyponatremia in humans and is called the syndrome of inappropriate antidiuresis (SIAD). To study physiological changes resulting from AVP overproduction and to develop an animal model of hyponatremia, the human AVP gene was expressed under the control of the metallothionein promoter in transgenic $(\mathrm{Tg})$ rats. Analyses of AVP immunoreactivity (irAVP) in the tissues revealed that the transgene is expressed mainly in the central nervous system. Gel filtration showed that irAVP in the brain and plasma was properly processed AVP. AVP purified from the brains of both $\mathrm{Tg}$ and control rats also exerted equal bioactivity to generate cAMP in LLC-PK1 cells. The founder rats did not show any physical or anatomical abnormalities. Under basal conditions, Tg rats
\end{abstract}

had high plasma AVP levels (Tg $13 \cdot 8 \pm 2 \cdot 5 \mathrm{pg} / \mathrm{ml}$; control $2 \cdot 7 \pm 1 \cdot 2 \mathrm{pg} / \mathrm{ml} ; n=6$ in both groups; means \pm S.E.M.), decreased urine volume, and normal plasma $\left[\mathrm{Na}^{+}\right]$. Hypertonic saline injected i.p. did not affect AVP secretion in $\mathrm{Tg}$ rats. In response to a zinc-supplemented liquid diet, plasma AVP decreased in control rats, but increased in $\mathrm{Tg}$ rats $(\mathrm{Tg} 32.7 \pm 2.7 \mathrm{pg} / \mathrm{ml}$; control $1 \cdot 0 \pm 0.1 \mathrm{pg} / \mathrm{ml} ; n=6)$, resulting in hyponatremia $(\mathrm{Tg}$ $135 \cdot 2 \pm 2 \cdot 5 \mathrm{mEq} / \mathrm{l}$; control $140 \cdot 8 \pm 0 \cdot 4 \mathrm{mEq} / \mathrm{l} ; n=6)$. To our knowledge, this is the first transgenic animal to show diluting hyponatremia. This transgenic rat may therefore provide a useful model in which to investigate various physiological alterations resulting from the oversecretion of AVP which involve SIAD, stress response, behavior, and blood pressure.

Journal of Endocrinology (2002) 173, 35-44

\section{Introduction}

Arginine vasopressin (AVP) is a nine amino acid neuropeptide that acts as the major antidiuretic hormone. It also has various functions, such as the maintenance of blood pressure, response to stress, and regulating circadian rhythm (Miller \& Moses 1971, Tausch et al. 1983), and behavior (Miller et al. 1995). AVP is synthesized in hypothalamic nuclei, including the supraoptic nucleus (SON), paraventricular nucleus (PVN), and suprachiasmatic nucleus (van Leeuwen et al. 1978, Swanson \& Sawchenko 1983, Miller et al. 1988). Magnocellular neurons in SON and PVN project to the neural lobe of the pituitary, where AVP is released into the circulation in response to hyperosmotic or hypovolemic stimuli (Majzoub 1985, Morris \& Alexander 1989). AVP elicits vasoconstriction via V1a receptors located in smooth muscle cells and water reabsorption at the renal collecting duct via V2 receptors (Brownstein 1983). Parvocellular neurons in the PVN project to the median eminence, where AVP is released into pituitary portal vessels in response to stress simultaneously with corticotropinreleasing factor (CRF) (Watabe et al. 1988). CRF and AVP are transported to the anterior lobe of the pituitary and promote pro-opiomelanocortin gene activation and adrenocorticotropin secretion. In both parvo- and magnocellular neurons, AVP is synthesized from a precursor (preproAVP) which consists of a signal peptide, AVP, neurophysin II, and a glycoprotein (Brownstein 1983, Schmale et al. 1983). PreproAVP is processed in secretory vesicles during axonal transport from the hypothalamus to the posterior pituitary (Brownstein et al. 1980).

Chronic oversecretion of AVP causes the syndrome of inappropriate antidiuresis (SIAD) which manifests in humans as hypervolemic hyponatremia (Zerbe et al. 1980, Kovacs \& Robertson 1992), the pathophysiology of which is unclear. An animal model of SIAD would be a useful tool in which to investigate the physiologic changes resulting from chronic hyponatremia. In recent years, the technique of pronuclear injection (Gordon et al. 1980, Gordon \& Ruddle 1981) has been used to incorporate a foreign gene into the genome of a host animal, thus 
enabling in vivo analysis of a gene as a whole animal model. Transgenic animals expressing the vasopressin gene have been used to conduct studies with two objectives. According to requirements, transgenes have been constructed differently. One aim was to investigate the normal physiology of the AVP gene (Murphy et al. 1987, Grant et al. 1993b, Miller et al. 1993, Zeng et al. 1994, Waller et al. 1996). To be a useful model of gene expression, the transgenes should include important cis-acting promoter and enhancer elements in addition to the structural gene (Grant et al. 1993b). Usually, they contain several kilobases of flanking sequences at each $5^{\prime}$ and $3^{\prime}$ end in addition to the $2.2 \mathrm{~kb}$ structural AVP gene. The other aim was to determine the role of the gene product in transgenic animals which overexpress the AVP gene. For that purpose, Habener et al. (1989) established a line of mice transgenic for mouse metallothionein I promoter-rat AVP structural gene. In these mice, the AVP level was 50- to 100-fold higher than in the control, and their AVP was mainly derived from the brain and correctly processed. However, serum $\mathrm{Na}$ levels remained within the normal range, and urine volumes were even elevated above normal. Habener et al. (1989) postulated that there would be renal resistance from long-term exposure to high levels of AVP in such transgenic mice.

In this study, we sought to produce a line of transgenic rats which overexpress the AVP gene, in order to investigate the physiological alterations resulting from sustained hypervasopressinemia. We used rats as the host animal, because they make physiological experiments, such as measuring plasma AVP, plasma $\left[\mathrm{Na}^{+}\right]$and urine volume, much easier. We constructed a fusion gene consisting of $0.77 \mathrm{~kb}$ of the heavy metal-inducible promoter region in the mouse metallothionein I gene (Durnam et al. 1980, Durnam \& Palmiter 1981, Hammer et al. 1985) and $2 \cdot 1 \mathrm{~kb}$ of the human AVP structural gene (Sausville et al. 1985) (mMT-hAVP), and a line of rats has been developed which is transgenic for the mMT-hAVP gene (abbreviated as $\mathrm{Tg}$ ). Homozygous offspring of one transgenic founder were studied to assess the expression of the transgene and physiological status. Under basal conditions, plasma AVP levels in $\mathrm{Tg}$ rats were five to ten times higher than in control rats. Zinc treatment further increased the AVP secretion by threefold over basal level. Here we analyze the expression of the transgene, the authenticity of the AVP from the transgene, and the physiological changes in water metabolism in Tg rats.

\section{Materials and Methods}

Construction of the mouse metallothionein I-human AVP fusion gene (mMT-hAVP gene)

One P1 phage clone that contains human AVP gene was identified by library screening (GSI P1-2535; Genome Systems Library Screening Service, St Louis, MO, USA) using polymerase chain reaction (PCR). Primers complementary to the $5^{\prime}$ untranslated region (UTR) and intron 1 of the human AVP gene ( $5^{\prime}$ tgcctgaatcactgctgacc gctggggacc $3^{\prime}, \quad 5^{\prime}$ gctatggctgccctgagatggcccacagtg $\left.3^{\prime}\right)$ were employed. PCR reactions were performed in $50 \mu \mathrm{l}$ volumes in $50 \mathrm{mM} \mathrm{KCl}, 10 \mathrm{mM}$ Tris- $\mathrm{HCl}(\mathrm{pH}$ 8.3), $1.5 \mathrm{mM} \mathrm{MgCl}$, and $1 \mathrm{U}$ rTaq polymerase (Takara, Tokyo, Japan). The following PCR conditions were used: 1 cycle at $94{ }^{\circ} \mathrm{C}(4 \mathrm{~min}), 35$ cycles at $94{ }^{\circ} \mathrm{C}(1 \mathrm{~min}), 53{ }^{\circ} \mathrm{C}$ $(1 \mathrm{~min})$ and $72{ }^{\circ} \mathrm{C}(3 \mathrm{~min})$, terminating with 1 cycle at $72{ }^{\circ} \mathrm{C}$ for $7 \mathrm{~min}$. From the $\mathrm{P} 1$ phage clone, we prepared a $2 \cdot 1 \mathrm{~kb}$ genomic fragment containing the entire coding region of AVP precursor, starting from 30 bases above the translation start site until the polyadenylation addition signal, by long and accurate PCR technology (LA-PCR kit). Primers complementary to $5^{\prime}$ UTR and $3^{\prime}$ UTR of the human AVP gene that were directed to have BamHI or EcoRI cloning sites were employed $\left(5^{\prime}\right.$ ccacggatccgtgctg catacggggtccac $3^{\prime}, \quad 5^{\prime}$ cattgaattcggtttattgtccgtgctgc $\left.3^{\prime}\right)$. The PCR conditions were the same as used in AVP gene screening. The entire sequence was identified by direct double strand cycle sequencing (BigDye terminator cycle sequencing kit; ABI, Foster City, CA, USA). A 0.77 kb EcoRI-Bgl II fragment containing the promoter fragment of the mouse metallothionein I was placed upstream of the $2 \cdot 1 \mathrm{~kb}$ BamHI-EcoRI fragment containing the human AVP structural gene (Fig. 1). The ligated material was digested with EcoRI and subcloned into plasmid vector pUC12.

\section{Generation of transgenic rats}

Transgenic rats were produced by DNA microinjection as described previously (Toyada \& Chang 1974, Hochi et al. 1990). The mMT-hAVP gene was injected into the male pronuclei of a total of 321 eggs of Sprague-Dawley rats in three separate experiments according to the method previously reported (Hochi et al. 1990). Two hundred and ninety-one of the eggs survived microinjection and incubation. Out of these, 289 eggs were transferred to 12 recipients. To identify transgenic founder animals, tail DNA from offspring was screened by PCR with the same primers as those used in $\mathrm{P} 1$ phage screening. By selective breeding, a line of transgenic rats was established with animals that were either homozygous or heterozygous for the rat transgene. To identify the copy number of the transgene, tail DNA from this line was digested with HindIII and KpnI, which recognizes two sites within the human genomic AVP gene, and analyzed by Southern blotting using a ${ }^{32} \mathrm{P}$ randomly labeled $0 \cdot 2 \mathrm{kbp}$ human AVP $5^{\prime}$ fragment as a probe.

\section{RT-PCR and nested PCR of human AVP $m R N A$ in various tissues in $\mathrm{Tg}$ rats}

Total cellular RNA was isolated from rat tissues by homogenization in TRIzol reagent (Gibco-BRL, Life 
(A)

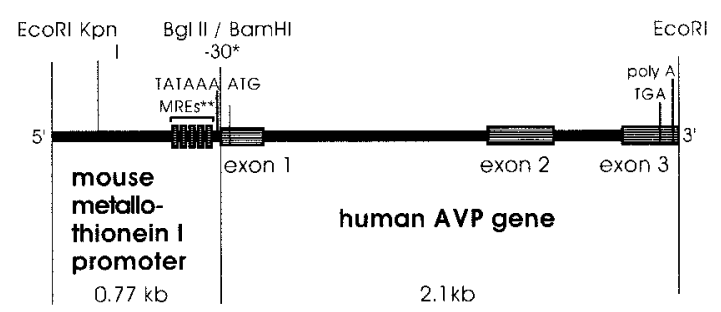

(B)

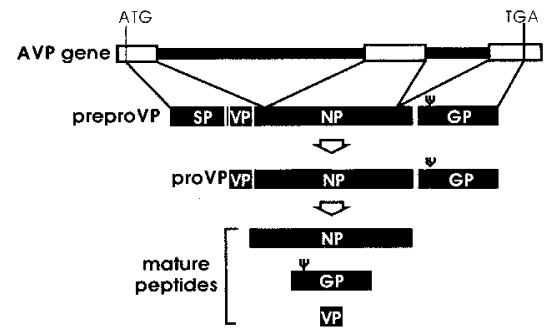

Figure 1 (A) Structure of mMt-hAVP fusion gene used for microinjection. The fusion gene contains $770 \mathrm{bp}$ mouse metallothionein I gene and $2 \cdot 1 \mathrm{~kb}$ human AVP structural gene. The $\mathrm{BamHI}$ and EcoRI sites were added by oligo-directed PCR.

$\mathrm{Bgl} \mathrm{II} / \mathrm{BamHI}$ indicates the site of the fusion between the mouse metallothionein I gene and the human AVP gene; this occurs in the 5' UTR of both genes. Consensus sequences involved in transcription initiation, translation initiation and termination, and polyadenylation are shown. ${ }^{*}-30$; the human AVP gene starts at $-30 \mathrm{bp}$ from the translation start site. ${ }^{* *}$ MREs; metal responsive elements. (B) Diagrams of the exon-intron structure of the AVP gene and pattern of processing of preproAVP to the mature peptides, AVP (VP), neurophysin II (NP) and the glycoprotein (GP) with one $\mathrm{N}$-glycosylation site $(\Psi)$. SP indicates signal peptide.

Technologies Inc., Rockville, MD, USA) and prepared according to the protocol provided by the manufacturer. Contaminating DNA was digested with DNase 1. Human AVP mRNA in various tissues in Tg rats was detected by RT-PCR (One Step RNA PCR Kit) using a primer pair complementary to exon 1 and exon 3 of human AVP (Table 1). Nested PCR was executed using a primer pair specific for the human AVP gene with gel-purified RT-PCR DNA fragment as a template (Table 1). Nested
Table 2 Tissue content of immunoreactive AVP (irAVP) in Tg and control rats. Values are means \pm S.E.M.; $n=6$

\begin{tabular}{|c|c|c|}
\hline & $\begin{array}{l}\text { Tg } \\
\text { (pg/g wet tissue) }\end{array}$ & $\begin{array}{l}\text { Control } \\
\text { (pg/g wet tissue) }\end{array}$ \\
\hline Total brain & $13224 \pm 795^{*}$ & $9930 \pm 601$ \\
\hline Pituitary† & $156000 \pm 28600$ & $141000 \pm 20200$ \\
\hline Heart & $43 \cdot 4 \pm 8 \cdot 5$ & UD \\
\hline Lung & $149 \cdot 0 \pm 37 \cdot 9$ & UD \\
\hline Liver & $22 \cdot 3 \pm 2 \cdot 2$ & UD \\
\hline Spleen & $46 \cdot 2 \pm 4 \cdot 1$ & UD \\
\hline Pancreas & $10 \cdot 3 \pm 2 \cdot 5$ & UD \\
\hline Kidney & $75 \cdot 1 \pm 5 \cdot 9$ & UD \\
\hline Testis & $62 \cdot 2 \pm 11 \cdot 8$ & UD \\
\hline
\end{tabular}

PCR fragments were subjected to restriction enzyme analysis and DNA sequencing to identify their origin. These PCR fragments were analyzed by $1 \cdot 0 \%$ agarose gel electrophoresis.

\section{Radioimmunoassay (RIA)}

Rats were decapitated and trunk blood was collected in chilled tubes containing EDTA potassium salt. Each tissue (see Table 2) was removed after complete exsanguination. AVP in plasma and tissue extracts was measured after first extracting it from the samples by use of C-18 octadecylsilica cartridges (Sep-Pak; Waters Associates, Milford, MA, USA). After elution with methanol, the resultant eluates were freeze-dried and resuspended in assay buffer. Samples from urine were directly diluted with assay buffer. All samples were assayed by a highly sensitive RIA with a detection limit of $0.1 \mathrm{pg} / \mathrm{ml}$ (AVP RIA kit; kindly provided by Mitsubishi Chemical Co. Ltd, Tokyo, Japan).

\section{Gel filtration and AVP RIA in tissues of $\mathrm{Tg}$ rats}

Rat tissues were extracted in $4 \%$ acetic acid, and supernatants were prepared by centrifugation twice at $2000 \mathrm{~g}$

Table 1 Primers used for RT-PCR and nested PCR

\begin{tabular}{|c|c|c|c|}
\hline & Location & $\begin{array}{l}\text { Expected length } \\
\text { (bp) }\end{array}$ & $\begin{array}{l}\text { Control enzyme } \\
\text { (expected length) }\end{array}$ \\
\hline \multicolumn{4}{|c|}{$\begin{array}{l}\text { Primers in sequence } \\
\text { (bp) }\end{array}$} \\
\hline F1: 237-258 & Exon 1 & F1/R1: 393 & \\
\hline R1: 2149-2172 & Exon3 & & \\
\hline F2: 281-306 & Exon 1 & F2/R2: 303 & Apa I; $(104,199)$ \\
\hline R2: 2099-2127 & Exon3 & & \\
\hline
\end{tabular}


for $15 \mathrm{~min}$ and $8000 \mathrm{~g}$ for $15 \mathrm{~min}$. Up to $1 \mathrm{ml}$ sample was loaded onto a $50 \times 2.5 \mathrm{~cm}$ column containing Bio-Gel P-10 equilibrated with $4 \%$ acetic acid and $0 \cdot 1 \%$ bovine serum albumin. Multiple $10 \mathrm{ml}$ fractions were collected over a period of $24 \mathrm{~h}$ at a flow rate of $20 \mathrm{ml} / \mathrm{h}$. Samples from each fraction were freeze-dried and subjected to AVP RIA without using the Sep-Pak C18 column.

\section{Bioactivity of AVP in brains}

The AVP bioassay was performed essentially as described previously (Habener et al. 1989). In brief, the LLC-PK1 renal tubular cell line was incubated with assay medium which consisted of Dulbecco's modified Eagle's medium supplemented with $100 \mu \mathrm{M}$ 3-isobutyl-L-methylxanthine together with each amount of standard AVP (Peptide Institute, Osaka, Japan) or aliquots of test samples. After a 30-min incubation, the cells and medium were harvested, and subjected to cAMP RIA (Cyclic AMP Assay Kit; Yamasa Shouyu KK, Tokyo, Japan).

\section{Metabolic studies}

The rats were raised and housed in clear plastic cages in an environmentally controlled room at a temperature of $23{ }^{\circ} \mathrm{C}$ and with alternating $12 \mathrm{~h}$ light (0900-2100 h) and $12 \mathrm{~h}$ darkness $(2100-0900 \mathrm{~h})$. All procedures were in accordance with institutional guidelines for animal care at Nagoya University School of Medicine, which conform with NIH Guidelines for the Care and Use of Laboratory Animals.

Basal measurement Male homozygous offspring of the $\mathrm{Tg}$ rats $(286 \pm 4 \mathrm{~g}, n=6)$ and transgene-negative control rats $(320 \pm 4 \mathrm{~g}, n=6)$ at 10 weeks of age were housed in metabolic cages and provided with standard rat chow and water ad libitum. After 2 days of habituation to the metabolic cage, water intake and urine volume were measured. Afterwards the rats were decapitated and plasma $\left[\mathrm{Na}^{+}\right]$and AVP measured. Daily urine volume and water intake were analyzed after correction for body weight.

\section{Intraperitoneal injection of hypertonic saline} Hypertonic saline $(600 \mathrm{mOsm} / \mathrm{kg}, 2 \%$ body weight (BW)) or isotonic saline $(290 \mathrm{mOsm} / \mathrm{kg}, 2 \% \mathrm{BW})$ were injected i.p. into six $\mathrm{Tg}$ and six control rats. Thirty minutes after the injection, all rats were decapitated for plasma AVP measurement.

Effect of water loading and zinc ion After habituation to the metabolic cage and $12 \mathrm{~h}$ of food deprivation, rats were provided with a volume equivalent to $30 \% \mathrm{BW}$ of a commercial, nutritionally balanced liquid diet (Isocal plus, Mead-Johnson, Evansville, IN, USA) supplemented with zinc ion to induce the metallothionein I promoter. This diet was of a nutritional composition that supplies
$0.75 \mathrm{kcal} / \mathrm{ml}$ consisting of $45 \%$ carbohydrate, $15 \%$ protein, $40 \%$ fat, with $7 \cdot 3 \mathrm{mEq} / 1 \mathrm{Na}$, vitamins, trace elements, and $6.25 \mathrm{mM}$ zinc sulfate. Water forms $89 \%$ of the total volume of the diet; this gives a water loading of $26.7 \mathrm{ml} /$ $100 \mathrm{~g} \mathrm{BW}$ per day, twice as much as the water intake for normal rats in basal condition. Rats were divided into three groups (six Tg and six control rats in each group) and decapitated at different times (before, $12 \mathrm{~h}$ after or $24 \mathrm{~h}$ after providing the zinc liquid diet) for measuring plasma AVP and plasma $\left[\mathrm{Na}^{+}\right]$.

\section{Statistical analysis}

Values are expressed as means \pm S.E.M. Statistical analysis was performed by ANOVA followed by Fisher's PLSD test for multiple comparisons. Student's $t$-test was used to compare data between two groups. P<0.05 was considered significant.

\section{Results}

\section{Generation of transgenic rats}

Transgenic rats overexpressing the human AVP gene product coupled to the mouse metallothionein I promoter (Fig. 1) were created. Thirteen transgenic rats were identified from 49 pups by PCR analysis of their tail DNA. Four founder transgenic rats were selected based on high levels of AVP immunoreactivity in urine (527-1813 pg/100 g BW per day) compared with the other nine rats (158-174 pg/100 g BW per day). These founders did not show any physical, anatomical or pathological changes considered likely to involve malformation in the central nervous system (CNS), tumorigenesis or arteriosclerosis. They were mated with age-matched Sprague-Dawley rats. As one of the founders was infertile and two of them did not transmit the transgene, only one line of rats homozygous for the transgene was generated by selective breeding. This line contained at least ten copies of the transgene, as determined by comparison of blotting intensities with control human AVP DNA.

\section{Tissue AVP content}

Extracts from each tissue sample were subjected to AVP RIA (Table 2). irAVP was undetectable in all peripheral tissues from control rats, but ranged from $149 \pm 37.9$ to $10 \cdot 3 \pm 2.5 \mathrm{pg} / \mathrm{g}$ wet tissue in $\mathrm{Tg}$ rats. The highest level was in the pituitary, but there was no significant difference between levels in Tg and control rats. The second highest level was in the brain (pituitary excluded) including the hypothalamus where SON and PVN are located. Moderately high levels were detected in the lung, and much lower levels in the heart, liver, spleen, pancreas, kidney, and testis in Tg rats. irAVP has been reported in 
(A)

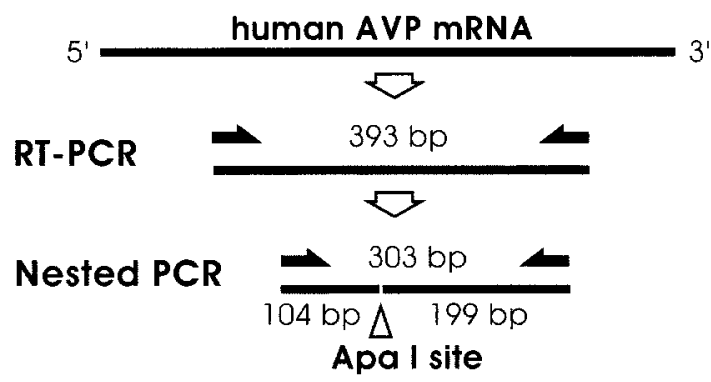

(B)

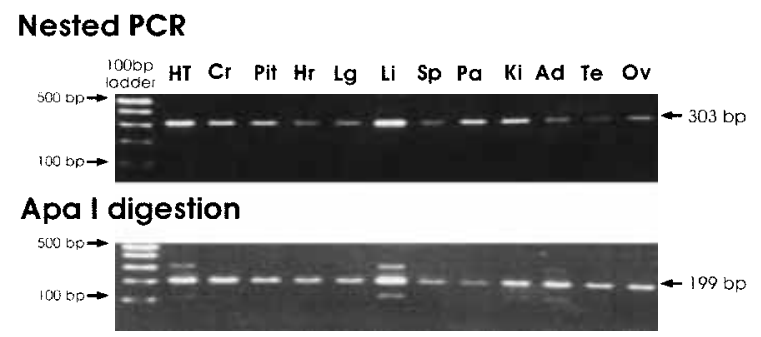

Figure 2 (A) Screening of human AVP mRNA expression in various tissues in Tg rats. Total RNA from each tissue was reverse transcribed and amplified by PCR for human AVP DNA specific primers (Table 1). Resultant fragments were gel purified, and subjected to nested PCR followed by Apa I digestion. (B) Upper panel: results of nested PCR of AVP cDNA. Lower panel: nested PCR digestion with restriction enzyme, Apa I, which is specific for human AVP cDNA. HT, hypothalamus; $\mathrm{Cr}$, cerebral cortex; Pit, whole pituitary; $\mathrm{Hr}$, heart; Lg, lung; Li, liver; Sp, spleen; $\mathrm{Pa}$, pancreas; Ki, kidney; Ad, adrenal glands; Te, testis; Ov, ovary.

pancreas and testis (Clements \& Funder 1986, Hawthorn et al. 1987) but little was found in control rats. The majority of AVP was therefore located in the brain of $\mathrm{Tg}$ rats. This was unexpected, because the majority of metallothionein promoter-regulated transgenes have been reported to be expressed more in the liver or kidney rather than in the CNS (Palmiter et al. 1982a, Hammer et al. 1985).

\section{RT-PCR and nested PCR of human AVP $m R N A$ in various tissues in $\mathrm{Tg}$ rats}

Nested PCR using primers located inside the first primers was performed. The fragments generated were identified by Apa I restriction enzyme digestion which is specific for human AVP cDNA (Fig. 2A). Human AVP cDNA was detected in the RT-PCR products of all the tissues tested (Fig. 2B). The sequences of nested PCR fragments were also identified by direct double strand cycle sequencing (data not shown). These data suggest that human AVP mRNA is ubiquitously expressed by the metallothionein I promoter in the tissues of $\mathrm{Tg}$ rats.
Gel filtration and AVP RIA in tissues of $\mathrm{Tg}$ rats

Gel filtration followed by RIA (Fig. 3) of tissues from $\mathrm{Tg}$ and control rats fed with zinc liquid diet for 2 days before they were killed showed that the majority of irAVP in the brain consisted of its completely processed form, and the peak level in Tg rats was twice that in control rats. In the liver, some irAVP species were completely processed AVP, but incompletely processed forms were also detected. The pancreas contained a substantial amount of properly processed AVP peptide and another peak in the void fraction thought to represent AVP molecules absorbed onto much larger proteins.

The irAVP in the plasma of $\mathrm{Tg}$ rats was completely processed AVP peptide. The peak level of the fractionation corresponded well to the plasma irAVP level. Most irAVP in the plasma therefore consisted of properly processed AVP with only a negligible amount of the incomplete form of AVP.

\section{Bioactivity of AVP in the brain}

Bioassay, in the LLC-PK1 porcine renal tubular cell line, of the AVP purified from the peak fraction in gel filtration-AVP RIA analyses showed that cAMP formation in response to the AVP from both Tg and control rats (Fig. 4) corresponded well with that of authentic AVP, indicating that AVP produced in the brains of $\mathrm{Tg}$ rats has normal bioactivity. As the data suggested that the brain is the major source of correctly processed AVP in Tg rats, it seems likely that plasma AVP would also have normal bioactivity.

\section{Metabolic studies}

Basal measurement In $\mathrm{Tg}$ rats under basal conditions, plasma AVP was extraordinarily high (Table 3), and daily urine volume and water intake were slightly decreased. There were no significant changes in plasma $\left[\mathrm{Na}^{+}\right]$and plasma total protein, which suggested that $\mathrm{Tg}$ rats do not show diluting hyponatremia when allowed to control their fluid intake.

Effect of hypertonic saline injection When hypertonic saline was injected intraperitoneally to the animals to see whether AVP secretion is regulated by plasma osmolality, plasma AVP in control animals significantly increased 30 min after the injection (Fig. 5) but there was no change in the high plasma AVP level in Tg rats.

Effect of zinc liquid diet To elucidate the simultaneous effect of water loading and induced secretion of AVP in water and electrolyte balance, a zinc-containing liquid diet was provided. Before being offered the diet, rats were deprived of food for $12 \mathrm{~h}$ in order to synchronize the onset of ingestion. Both $\mathrm{Tg}$ and control rats ingested all of the 

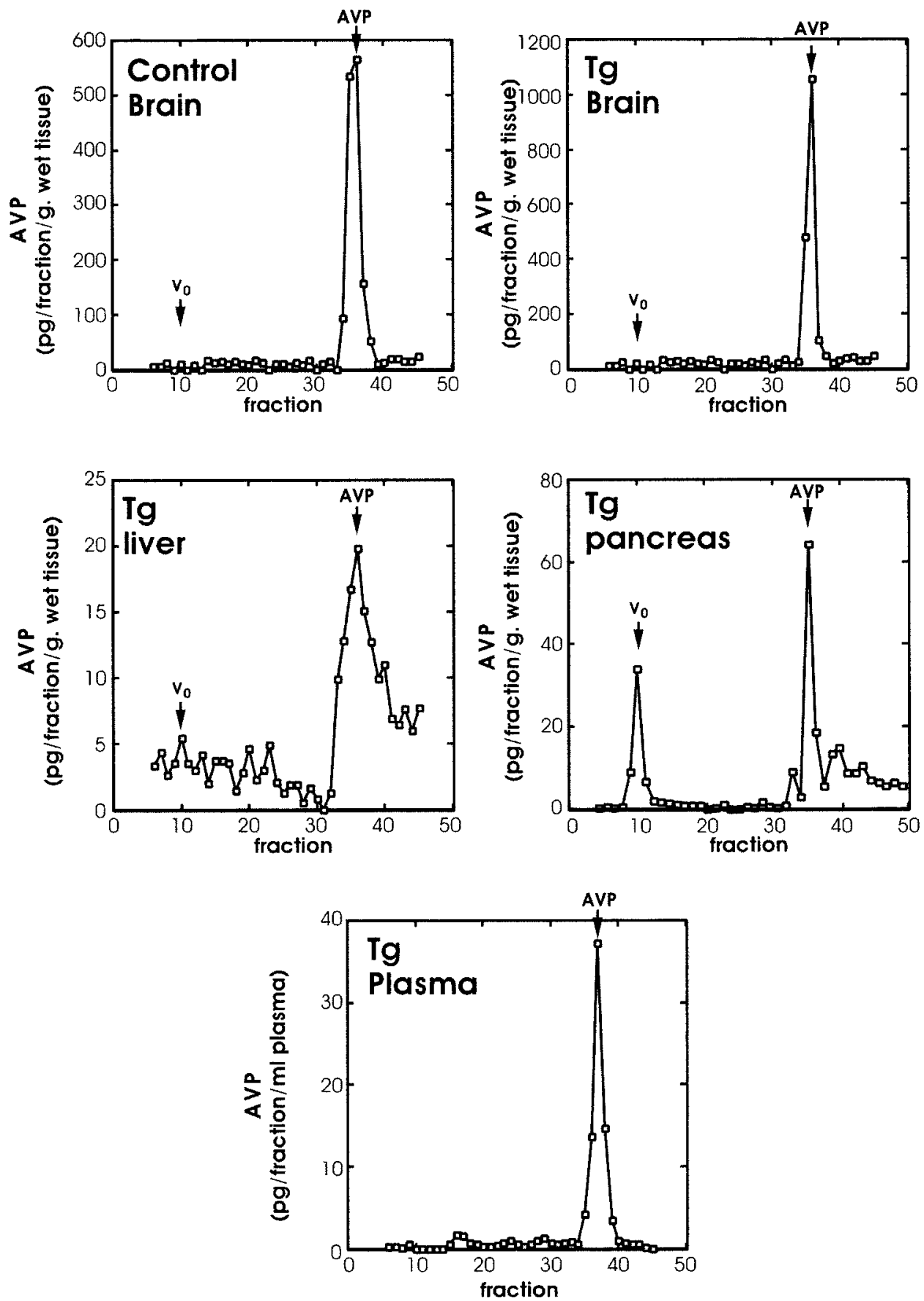

Figure 3 Gel filtration and AVP RIA in tissues of Tg rats. Arrows indicate elution positions of markers of authentic AVP and void volume of columns $\left(\mathrm{V}_{0}\right)$. All rats were provided with zinc liquid diet for 2 days before they were killed.

diet within the first few hours of administration. In the first $12 \mathrm{~h}$ after ingesting the liquid diet, both control and $\mathrm{Tg}$ rats showed massive diuresis (Fig. 6A) but urine excretion by $\mathrm{Tg}$ rats was significantly less compared with control rats. The time-course of the urine output showed that the effective water loading was limited to $12 \mathrm{~h}$. In control rats, plasma AVP at $12 \mathrm{~h}$ was suppressed due to the water loading, and had returned to normal after water loadinginduced diuresis had ended (Fig. 6B). In contrast, AVP secretion in $\mathrm{Tg}$ rats was significantly enhanced at $12 \mathrm{~h}$ in 


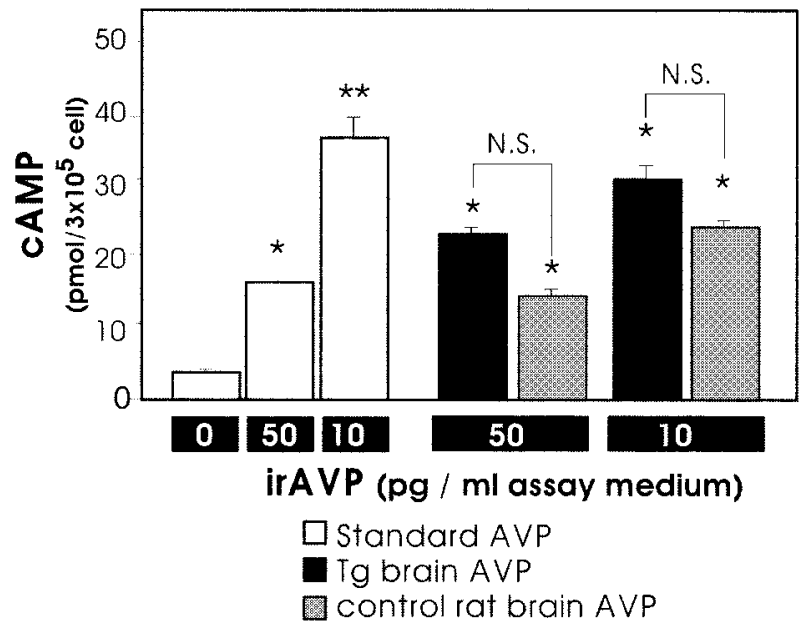

Figure 4 Bioactivity of AVP in the brain. AVP was purified from the peak fraction in gel filtration AVP RIA. CAMP formation in LLC-PK1 cells in response to the purified AVP (50 or $100 \mathrm{pg} / \mathrm{ml}$ ) was assayed in triplicate and compared with the effect of authentic AVP purified by the same method. ${ }^{*} P<0.05$ vs control. ${ }^{*} P<0 \cdot 01$ vs control. N.S., not significant.

spite of the water loading, and remained at a high level at $24 \mathrm{~h}$. Plasma $\left[\mathrm{Na}^{+}\right]$level in control rats stayed within normal levels at $24 \mathrm{~h}$, but $\mathrm{Tg}$ rats showed significant hyponatremia $(135 \pm 2.5 \mathrm{mEq} / \mathrm{l})$ after $24 \mathrm{~h}$ of liquid diet ingestion (Fig. 6C). Neither group had diarrhea and there were no apparent differences in the state of the feces. These results suggest that water loading can cause transitory diluting hyponatremia in $\mathrm{Tg}$ rats overexpressing the mMT-hAVP gene.

\section{Discussion}

In recent years, transgene technology has been utilized to produce animals that overexpress AVP to explore whether chronic oversecretion of vasopressin from the earliest stage of life would cause SIAD or alterations in the neuroendocrine systems thought to involve stress response, memory, and circadian rhythms. However, mice transgenic for a mouse metallothionein I promoter-rat vasopressin fusion

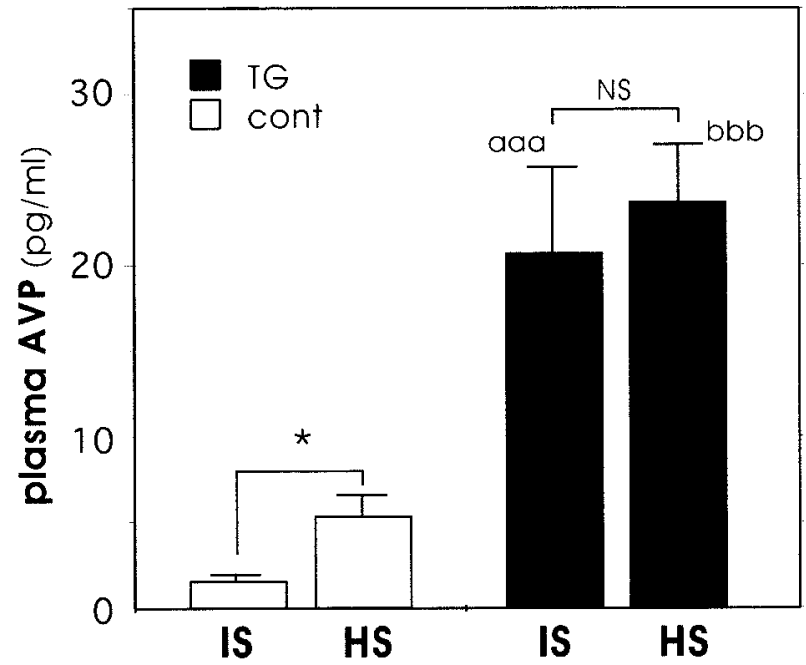

Figure 5 Plasma AVP 30 min after osmotic stimulus. Hypertonic saline (HS; $600 \mathrm{mOsm} / \mathrm{kg} \% \mathrm{BW}$ ) or isotonic saline (IS; $290 \mathrm{mOsm} / \mathrm{kg} \%$ BW) was injected i.p. into six Tg and six control rats. ${ }^{*} P<0.05$ vs isotonic saline. aaa $P<0 \cdot 001$ vs isotonic saline-injected control rats. ${ }^{\text {bbb }} P<0 \cdot 001$ vs hypertonic saline-injected control rats.

gene (Habener et al. 1989) expressed diabetes insipidus due to the lack of vasopressin sensitivity in the kidney despite extremely high plasma AVP. Furthermore, mice transgenic for a fusion of $5^{\prime}$ upstream sequences of the bovine vasopressin gene and the large $\mathrm{T}$-antigen promoter of simian virus 40 (Murphy et al. 1987), and mice transgenic for an $8.2 \mathrm{~kb}$ fragment of the rat AVP gene (Grant et al. 1993a, Miller et al. 1993) which secreted five times more AVP did not show hyponatremia or water retention. Interestingly, the latter mice showed enhanced attention and alertness, supporting earlier observations on the effects of AVP on behavior and cognitive function (Miller et al. 1995).

In the present study, we sought to produce transgenic rats that would overexpress AVP, because it is easier to analyze the physiological status and carry out plasma or urine AVP assays in rats than in mice. Compared with control rats, the basal plasma irAVP level in Tg rats was elevated four to six times and increased a further three- to

Table 3 Physiological parameters associated with water balance under basal conditions. All data were measured between 48 and 72 h. Values are means \pm S.E.M.; $n=6$
Urine volume $(\mathrm{ml} / 100 \mathrm{~g}$ BW per day) Water intake $(\mathrm{ml} / 100 \mathrm{~g}$ BW per day) Plasma $\left[\mathrm{Na}^{+}\right](\mathrm{mEq} / \mathrm{l})$ Plasma AVP (pg/ml) Plasma total protein $(\mathrm{g} / \mathrm{dl})$

\begin{tabular}{|c|c|}
\hline Tg & Control \\
\hline $3 \cdot 4 \pm 0 \cdot 4^{*}$ & $4 \cdot 8 \pm 0 \cdot 1$ \\
\hline $11 \cdot 5 \pm 0 \cdot 2^{*}$ & $13 \cdot 1 \pm 0 \cdot 5$ \\
\hline $141 \cdot 4 \pm 0 \cdot 7$ & $140 \cdot 4 \pm 0 \cdot 5$ \\
\hline $13 \cdot 8 \pm 2 \cdot 5^{*}$ & $2 \cdot 7 \pm 1 \cdot 2$ \\
\hline $7 \cdot 10 \pm 0 \cdot 15$ & $6.93 \pm 0.06$ \\
\hline
\end{tabular}

Male rats were provided with standard rat chow and water ad libitum in metabolic cages for 3 days. ${ }^{*} P<0 \cdot 05$ vs control. 
(A)

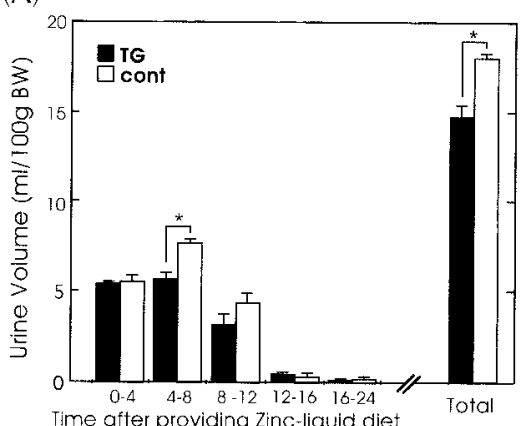

Time after providing Zinc-liquid diet

B)

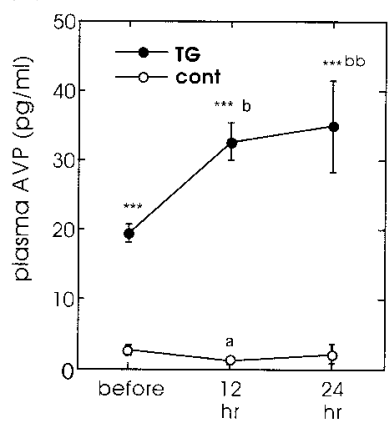

(C)

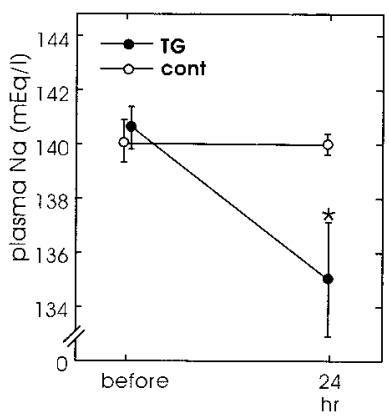

Figure 6 (A) Urine volume, (B) plasma AVP, and plasma (C) $\left[\mathrm{Na}^{+}\right]$ after water loading and zinc administration. Rats (six $\mathrm{Tg}$ and six control) were provided with zinc liquid diet (30\% BW) after $12 \mathrm{~h}$ of food deprivation. ${ }^{*} P<0.05$ vs control. ${ }^{* * *} P<0.001$ vs control. ${ }^{\mathrm{a}} P<0.05$ vs control rats before ingesting zinc liquid diet. ${ }^{\mathrm{b}} P<0.05$ vs $\mathrm{Tg}$ rats before ingesting zinc liquid diet. ${ }^{\mathrm{b}} \mathrm{P} P<0 \cdot 01 \mathrm{vs} \mathrm{Tg}$ rats before ingesting zinc liquid diet.

fourfold after zinc treatment. This suggests that the human AVP gene is influenced by the metallothionein I promoter even under basal conditions as well as being induced by zinc. In contrast, i.p. injection of hypertonic saline did not increase plasma AVP level in Tg rats, indicating that the transgene is not regulated by osmolality.

Under basal conditions, $\mathrm{Tg}$ rats did not show the diluting hyponatremia symptoms seen in SIAD patients. The decreased urine output and water intake in $\mathrm{Tg}$ rats indicates that $\mathrm{Tg}$ rats adapted to hypervasopressinemia by reducing water intake in order to prevent diluting hyponatremia. This reinforces the view that rats drink only as much as they need, and do not drink habitually or socially as humans do. However, the decrease in water intake and urine output was rather limited. Therefore, other mechanisms, for example in the kidney, might explain the adaptation. Verbalis \& Drutarosky (1988) reported that sustained administration of AVP and water loading results in free water retention and progressive hyponatremia for several days, but is followed by escape from the AVP-induced antidiuresis. The escape involves suppression of aquaporin 2 expression in the collecting duct (Ecelbarger et al. 1997), associated with a decrease in
V2 receptor mRNA (Murase et al. 1999) and protein (Tian et al. 2000). We have analyzed the precise mechanisms for such 'vasopressin tolerance' status in Tg rats (Yokoi et al. 2002).

However, significant induction of hyponatremia was induced in Tg rats by administration of a zinc liquid diet. Presumably, Tg rats were more hydrated because both groups of rats ingested the same amount of liquid diet (with no additional water supply) and the urine volume was significantly decreased in $\mathrm{Tg}$ rats. Acute induction of AVP secretion combined with water loading therefore appears to cause diluting hyponatremia in $\mathrm{Tg}$ rats. This is supported by Yokoi et al. (2002), who revealed a decrease in plasma total protein after the zinc liquid diet.

Analysis of irAVP content in various tissues showed that, in Tg rats, irAVP could be detected in all peripheral tissues but was highest in the brain, whereas, in control rats, it was undetectable in tissues other than the brain. The finding of the majority of AVP in the brain of Tg rats was unexpected, because the majority of metallothionein promoter-regulated transgenes are expressed more in the liver or kidney than in the CNS (Palmiter et al. 1982a, Hammer et al. 1985).

In Tg rats, irAVP in the brain was 100 - to 500-fold higher than in other tissues tested (c.f. Habener et al. 1989). In contrast, the irAVP content in the pituitary of $\mathrm{Tg}$ rats was similar to that of control rats and therefore did not reflect the overproduction of AVP in the brain. Three explanations for this discrepancy are possible: (1) the turnover of AVP is so fast in Tg rats that the AVP content of their pituitaries is limited; (2) heterologously expressed AVP (AVP mRNA was identified in brain cortex) may not be transported to the pituitary; and (3) expression of transgene-derived human AVP is likely to suppress endogenous rat AVP.

RT-PCR and nested PCR study are not quantitative but they did detect AVP mRNA ubiquitously in the tissues of Tg rats, which corresponds to the wide distribution of irAVP as shown previously with the mouse metallothionein promoter (Palmiter et al. 1982a,b, Habener et al. 1989). Studies in transgenic animals have revealed important findings regarding tissue-specific expression of the AVP gene. Habener et al. (1989) speculated that the octameric sequence $5^{\prime}$ GCCCAGCC3' between the TATA box and the cap site in the rat AVP gene is important in neuronal expression. Grant et al. (1993a) demonstrated normotopic expression of AVP mRNA in mice transgenic for an $8.2 \mathrm{~kb}$ fragment of the rat AVP gene that had $3 \mathrm{~kb}$ each of $5^{\prime}$ and $3^{\prime}$ ends of UTR. Waller et al. (1996) reported that rat transgenic for 5-VCAT-3 (rat vasopressin CAT fusion gene flanked by $5 \mathrm{~kb}$ of upstream and $3 \mathrm{~kb}$ of downstream vasopressin gene sequence) expressed tagged rat AVP polypeptide in hypothalamic neurons. Our study aimed to produce rats transgenic for an inducible AVP gene that would be expressed not only in normal but also in ectopic sites. 
Therefore, we placed the mouse metallothionein I promoter region $30 \mathrm{bp}$ upstream of the translation initiation site of the human AVP structural gene. Although the human AVP gene does not contain the octameric sequence present in the $5^{\prime}$ UTR of the rat AVP gene, we deleted most of the $5^{\prime}$ and $3^{\prime}$ UTR in the transgene construction. As we have developed only a single line of $\mathrm{Tg}$ rat, we must be cautious concerning the regulation of the AVP gene. However, in Tg rats, increased expression of irAVP was found only in the brain, and the distribution of irAVP did not coincide well with the pattern predicted for a metallothionein-regulated gene. It is therefore possible that DNA elements located outside of the $5^{\prime}$ and $3^{\prime}$ UTR, yet present within the AVP intron or coding regions, contribute to the specific expression of the AVP gene in the CNS.

Gel filtration and bioactivity studies in LLC-PK1 cells showed that proAVP was processed efficiently in the brain, but less so in pancreas and liver. Most irAVP in the plasma was properly processed AVP, but much larger proteins with AVP immunoreactivity were identified in the pancreas and liver. Two explanations are possible: either larger AVP immunoreactive proteins in the plasma were undetectable, or such proteins were not secreted into the circulation, but were retained or digested within the cell. The bioactivity of the AVP from Tg brains was identical to that in control rats and to authentic AVP. Most AVP in the plasma of Tg rats was therefore produced in the CNS.

In conclusion, we have developed a line of transgenic rat that secretes five or more times more AVP than normal, and which develops hyponatremia in response to water loading combined with further plasma AVP elevation. These rats may provide opportunities to investigate the physiological consequences of overproduction of AVP, and the numerous mechanisms that modulate water and mineral balance, blood pressure, behavior, autonomic, and neuroendocrine systems.

\section{Acknowledgements}

We wish to thank Dr Hideki Katakami for his technical advice on transgene construction and for providing a mouse metallothionein I gene, and Professor Shonen Yoshida and Dr Motoshi Suzuki for their technical help in gel filtration. This work was supported in part by the Research for the Future Program, the Japan Society for the Promotion of Science (JSPS-RFTF97I00201) and by a Grant-in-Aid for Scientific Research (B) from the Ministry of Education, Science, and Culture, Japan (08457263).

\section{References}

Brownstein MJ 1983 Biosynthesis of vasopressin and oxytocin. Annual Review of Physiology 45 129-135.
Brownstein MJ, Russell JT \& Gainer H 1980 Synthesis, transport, and release of posterior pituitary hormones. Science 207 373-378.

Clements JA \& Funder JW 1986 Arginine vasopressin (AVP) and AVP-like immunoreactivity in peripheral tissues. Endocrine Reviews 7 449-460.

Durnam DM \& Palmiter RD 1981 Transcriptional regulation of the mouse metallothionein-I gene by heavy metals. Journal of Biological Chemistry 256 5712-5716.

Durnam DM, Perrin F, Gannon F \& Palmiter RD 1980 Isolation and characterization of the mouse metallothionein-I gene. PNAS 77 6511-6515.

Ecelbarger CA, Nielsen S, Olson BR, Murase T, Baker EA, Knepper MA \& Verbalis JG 1997 Role of renal aquaporins in escape from vasopressin-induced antidiuresis in rat. Journal of Clinical Investigation 99 1852-1863.

Gordon JW \& Ruddle FH 1981 Integration and stable germ line transmission of genes injected into mouse pronuclei. Science 214 1244-1246.

Gordon JW, Scangos GA, Plotkin DJ, Barbosa JA \& Ruddle FH 1980 Genetic transformation of mouse embryos by microinjection of purified DNA. PNAS 77 7380-7384.

Grant FD, Reventos J, Gordon JW, Kawabata S, Miller M \& Majzoub JA 1993a Expression of the rat arginine vasopressin gene in transgenic mice. Molecular Endocrinology 7 659-667.

Grant FD, Reventos J, Kawabata S, Miller M, Gordon JW \& Majzoub JA $1993 b$ Transgenic mouse models of vasopressin expression. Hypertension 22 640-645.

Habener JF, Cwikel BJ, Hermann H, Hammer RE, Palmiter RD \& Brinster RL 1989 Metallothionein-vasopressin fusion gene expression in transgenic mice. Nephrogenic diabetes insipidus and brain transcripts localized to magnocellular neurons. Journal of Biological Chemistry 264 18844-18852.

Hammer RE, Brinster RL, Rosenfeld MG, Evans RM \& Mayo KE 1985 Expression of human growth hormone-releasing factor in transgenic mice results in increased somatic growth. Nature $\mathbf{3 1 5}$ 413-416.

Hawthorn J, Nussey SS, Henderson JR \& Jenkins JS 1987 Immunohistochemical localization of oxytocin and vasopressin in the adrenal glands of rat, cow, hamster and guinea pig. Cell and Tissue Research 250 1-6.

Hochi S, Ninomiya T, Honma M \& Yuki A 1990 Successful production of transgenic rat. Animal Biotechnology 1 175-184.

Kovacs L \& Robertson GL 1992 Syndrome of inappropriate antidiuresis. Endocrinology and Metabolism Clinics of North America 21 859-875

van Leeuwen FW, Swaab DF \& de Raay C 1978 Immunoelectronmicroscopic localization of vasopressin in the rat suprachiasmatic nucleus. Cell and Tissue Research 193 1-10.

Majzoub JA 1985 Vasopressin Biosynthesis. In Vasopressin, pp 465-474. Ed. RS Schrier. New York: Raven Press.

Miller M \& Moses AM 1971 Radioimmunoassay of urinary antidiuretic hormone with application to study of the Brattleboro rat. Endocrinology 88 1389-1396.

Miller MA, Zoeller RT \& Dorsa DM 1988 Detection of vasopressin messenger RNA in cells within the bed nucleus of the stria terminalis by in situ hybridization histochemistry. Neuroscience Letters 94 264-268.

Miller M, Kawabata S, Wiltshire-Clement M, Reventos J \& Gordon JW 1993 Increased vasopressin secretion and release in mice transgenic for the rat arginine vasopressin gene. Neuroendocrinology 57 621-625.

Miller M, Haroutunian V \& Wiltshire-Clement M 1995 Altered alertness of vasopressin-secreting transgenic mice. Peptides $\mathbf{1 6}$ $1329-1333$.

Morris M \& Alexander N 1989 Baroreceptor influences on oxytocin and vasopressin secretion. Hypertension 13 110-114.

Murase T, Ecelbarger CA, Baker EA, Tian Y, Knepper MA \& Verbalis JG 1999 Kidney aquaporin-2 expression during escape 
from antidiuresis is not related to plasma or tissue osmolality. Journal of the American Society of Nephrology 10 2067-2075.

Murphy D, Bishop A, Rindi G, Murphy MN, Stamp GW, Hanson J, Polak JM \& Hogan B 1987 Mice transgenic for a vasopressinSV40 hybrid oncogene develop tumors of the endocrine pancreas and the anterior pituitary. A possible model for human multiple endocrine neoplasia type 1. American Journal of Pathology 129 552-566.

Palmiter RD, Brinster RL, Hammer RE, Trumbauer ME, Rosenfeld MG, Birnberg NC \& Evans RM 1982a Dramatic growth of mice that develop from eggs microinjected with metallothionein-growth hormone fusion genes. Nature 300 611-615.

Palmiter RD, Chen HY \& Brinster RL $1982 b$ Differential regulation of metallothionein-thymidine kinase fusion genes in transgenic mice and their offspring. Cell 29 701-710.

Sausville E, Carney D \& Battey J 1985 The human vasopressin gene is linked to the oxytocin gene and is selectively expressed in a cultured lung cancer cell line. Journal of Biological Chemistry 260 10236-10241.

Schmale H, Heinsohn S \& Richter D 1983 Structural organization of the rat gene for the arginine vasopressin-neurophysin. EMBO Journal 2 763-767.

Swanson LW \& Sawchenko PE 1983 Hypothalamic integration: organization of the paraventricular and supraoptic nuclei. Annual Review of Neuroscience 6 269-324.

Tausch A, Stegner H, Leake RD, Artman HG \& Fisher DA 1983 Radioimmunoassay of arginine vasopressin in urine: development and application. Journal of Clinical Endocrinology and Metabolism $\mathbf{5 7}$ 777-781.

Tian Y, Sandberg K, Murase T, Baker EA, Speth RC \& Verbalis JG 2000 Vasopressin V2 receptor binding is down-regulated during renal escape from vasopressin-induced antidiuresis. Endocrinology 141 307-314.

Toyada Y \& Chang M 1974 Fertilization of rat eggs in vitro by epididymal spermatozoa and the development of eggs following transfer. Journal of Reproduction and Fertility 36 9-12.

Verbalis JG \& Drutarosky MD 1988 Adaptation to chronic hypoosmolality in rats. Kidney International 34 351-360.

Waller S, Fairhall KM, Xu J, Robinson IC \& Murphy D 1996 Neurohypophyseal and fluid homeostasis in transgenic rats expressing a tagged rat vasopressin prepropeptide in hypothalamic neurons. Endocrinology 137 5068-5077.

Watabe T, Tanaka K, Kumagae M, Itoh S, Kogure M, Hasegawa M, Horiuchi T, Morio K, Takeda F, Ubukata E et al. 1988 Role of endogenous arginine vasopressin in potentiating corticotropinreleasing hormone-stimulated corticotropin secretion in man. Journal of Clinical Endocrinology and Metabolism 66 1132-1137.

Yokoi H, Nagasaki H, Tachikawa K, Arima H, Murase T, Miura Y, Hirabayashi M \& Oiso Y 2002 Adaptation to sustained high plasma vasopressin in water and electrolyte homeostasis in the rat transgenic for the metallothionein-vasopressin fusion gene. Journal of Endocrinology 173 23-33.

Zeng Q, Carter DA \& Murphy D 1994 Cell specific expression of a vasopressin transgene in rats. Journal of Neuroendocrinology 6 469-477.

Zerbe R, Stropes L \& Robertson G 1980 Vasopressin function in the syndrome of inappropriate antidiuresis. Annual Review of Medicine 31 315-327.

Received 8 October 2001

Accepted 19 December 2001 